Article

\title{
Anti-LID Process with a Remote Direct Heating Method Using a Half-Bridge Resonance Circuit for a PERC Solar Cell Module
}

\author{
Soo Min Kim ${ }^{\circledR}$, Sanghoon Jung, Yoonkap Kim * and Junhee Kim * \\ Convergence Materials Research Center, Innovative Technology Research Division, \\ Gumi Electronics and Information Technology Research Institute (GERI), Gumi 39171, Korea; \\ smkim83@geri.re.kr (S.M.K.); shjung@geri.re.kr (S.J.) \\ * Correspondence: yoonkap@geri.re.kr (Y.K.); junhee.kim@geri.re.kr (J.K.); \\ Tel.: +82-54-479-2120 (Y.K.); +82-54-479-2127 (J.K.)
}

Received: 27 November 2019; Accepted: 17 December 2019; Published: 24 December 2019

check for updates

\begin{abstract}
As the importance of the levelized cost of electricity (LCOE) increases in the solar cell industry, the demand for high-efficiency solar cells is rapidly increasing. Typically, p-type passivated emitter rear contact (PERC) solar cells are the most commonly used in the industry, and their efficiency is approximately $22-23 \%$. P-type solar cells are reported to exhibit a light-induced degradation (LID) phenomenon, in which their output constantly decreases during power generation under solar radiation, and the output significantly reduces as their reference efficiency increases. Ultra-high-efficiency solar cells, which are on high demand, have a considerable output reduction due to the LID phenomenon; hence, technologies to prevent the LID phenomenon are required. However, research on this phenomenon has not been conducted because there is no method to transfer heat to solar cells inside the encapsulant when the modules are produced. In this study, a regeneration state was formed by remotely heating solar cells without damaging the encapsulant of the solar cell module. This was accomplished by using a heating method based on an induction magnetic field. A half-bridge resonance circuit was used to apply the induction magnetic field, and the temperature of the solar cell was controlled by adjusting the magnitude of the current flowing through the coil. To determine whether only the solar cell was heated, the temperature distribution inside the module was analyzed using an IR camera. The minority carrier lifetime was examined by real-time observation of the open-circuit voltage pattern of the solar cell. Finally, the observed real-time open-circuit voltage data were used, and dynamic simulation of the regeneration process was applied to analyze the LID activation energy generated in the regeneration process of the solar cell module. In conclusion, research was conducted on applying the regeneration state to prevent the LID phenomenon in the solar-cell-module stage, and the LID activation energy of the solar cell module was extracted. Based on this, a nondestructive degradation prevention technology for the solar cell module was developed.
\end{abstract}

Keywords: solar cell; solar module; light-induced degradation; regeneration; remote heating; half-bridge resonance circuit

\section{Introduction}

In the solar cell industry, the economic efficiency of the energy of a power source has been compared using the levelized cost of electricity (LCOE) of the solar cell rather than its power output. In the case of solar cells, which are used as power sources, the performance warranty period is longer than 25 years. Thus, most of them are installed for long-term power generation. The ratio 
of the produced power to the initial installation cost has been considered in many cases to improve the power generation performance over time [1]. Therefore, despite its high initial cost, a solar cell module with long-term stability is economical because of its lower LCOE. From the perspective of the LCOE, the most vital element is the technology for degradation prevention. The main causes of degradation include encapsulant corrosion, potential-induced degradation (PID), and light-induced degradation (LID). Among them, PID can be prevented by improving the properties of the encapsulant. Therefore, solutions for the improvement of materials are being researched in the solar-cell-module field. As the improvement of the encapsulant improves the performance degradation caused by moisture penetration and discoloration, most degradation prevention technologies have been focused on improving the encapsulant.

When the degradation characteristics of industrially used solar cell modules were analyzed, it was found that the annual degradation rate of the modules reached $0.7 \%$. A road map to reduce it to $0.5 \%$ by 2021 is being established [1]. Outdoor solar cell modules exhibit nonlinear degradation, where more degradation occurs at the beginning rather than during the linear performance degradation each year. When solar cell modules are installed outdoors for power generation, the degradation rate during the first year is approximately $2.5 \%$ [1]. This initial degradation appears to be mostly caused by the LID phenomenon, and there is still no appropriate LID mitigation technology.

Generally, solar cells that use p-type Czochralski (Cz) silicon substrates containing boron, the LID phenomenon, where the output continuously decreases under solar radiation, has been reported. The LID phenomenon, which was first reported by Fischer in 1974, is caused by the boron oxide complex $\left(\mathrm{B}_{s} \mathrm{O}_{2 i}\right)$, which is generated by the combination of the substitutional boron $\left(\mathrm{B}_{s}\right)$ and interstitial oxygen dimer $\left(\mathrm{O}_{2 i}\right)$ of silicon substrates [2-4]. The boron oxide complex continuously disintegrates the electron-hole pairs, which are generated when photons enter the solar cell, through a self-trapping-enhanced carrier recombination mechanism [2-4]. The LID phenomenon has a larger impact on high-efficiency solar cells, such as PERC solar cells, and it has been reported, based on laboratory data, that an output degradation of approximately $10 \%$ of the overall efficiency occurs [5-7].

Various methods have been researched to address the LID phenomenon, and the representative method is the application of a $200{ }^{\circ} \mathrm{C}$ temperature for $10 \mathrm{~min}$ in the dark state, which was found to recover the reduced output to the original state. However, this LID recovery process cannot be used as a fundamental solution, because the LID phenomenon occurs again when sunlight is irradiated [8].

As the LID process of solar cells occurs because of the bi-stable state of the boron oxide complex, research was conducted on using substances other than boron for solar cell doping [4]. The representative substances include germanium, gallium, and phosphorus. Unlike the boron oxide complex, they were found to have a monostable state and did not exhibit the LID phenomenon. However, it is difficult to use germanium and gallium dopant because they are expensive materials. Phosphorus is used to produce n-type solar cells, but it has a low yield because the variation in resistivity according to the height is large during the formation of ingots compared to the p-type that uses boron; this is due to the difference in the segregation factor.

Because a method to resolve the LID phenomenon permanently could not be achieved through an industrial breakthrough, Herguth et al. published a new recovery method $[9,10]$. This work described a regeneration state in which solar cells exhibit the LID phenomenon at the beginning of continuous exposure to an AM1.5G solar source while exposed to temperatures higher than $90{ }^{\circ} \mathrm{C}$. However, this later showed slow recovery, resulting in no additional occurrence of the LID phenomenon at room temperature.

However, the regeneration state does not persist. The initial state is recovered when annealing is performed in the dark state $\left(>100{ }^{\circ} \mathrm{C}\right)$, and the LID phenomenon later occurs [11]. The regeneration process is a metastable state because of the initialization phenomenon, and further research on the formation of the regeneration state has been conducted. Problems with the initialization phenomenon are created during the solar-cell-module production process. Even if the regeneration state is activated in the solar cell stage by consuming considerable energy, the lamination process ( $\left.>160^{\circ} \mathrm{C}, 20 \mathrm{~min}\right)$ of 
the solar cell module causes initialization, resulting in the LID phenomenon. In conclusion, methods for activating the regeneration state upon the completion of the solar-cell-module process are required to address this problem, but no specific method has been published.

In this study, a method of inducing the regeneration state in a solar-cell-module structure was developed to address this problem, and a system for monitoring the regeneration state induction process in real time was constructed. Furthermore, the real-time induction process measured through kinetic modeling was analyzed, and it was found that the results agreed with those of previous studies on LID activation energy. Air heating is used to increase the temperature of the solar cell module stage. In this method, heat is transferred from the outside of the module to the inside. Therefore, when the temperature of the solar cell is maintained at a high level, the encapsulant is exposed to a higher temperature, resulting in higher deformation or damage risk. Moreover, it takes a considerable amount of time to sufficiently heat the solar cell inside the module owing to the low thermal conductivity of the encapsulant, and cooling after regeneration activation also requires a long time, which may cause complications.

In this work, only the solar cell inside the module was selectively heated using remote heating based on an induction magnetic field. To perform remote heating, a half-bridge resonance circuit and a copper coil with the same size as the solar-cell-area size were applied. When remote heating through the resonance circuit was applied, only the aluminum used as the electrode on the back of the solar cell was selectively heated. A uniform temperature distribution on the silicon solar-cell substrate with high thermal conductivity was observed. When remote heating using the resonance circuit was applied, only the aluminum used as the electrode at the back of the solar cell was selectively heated. A uniform temperature distribution on the silicon solar-cell substrate with high thermal conductivity was observed. Unlike air heating, remote heating can minimize damage to the encapsulant because heating is applied to the inside. Energy efficiency is improved because only the targeted solar cell is selectively heated, and there is economic efficiency because the temperature can be increased rapidly using resonance heating. In the resonance heating method, the regeneration process signal of the solar cell was filtered by removing the alternating current (AC) noise generated by a regular change in the direction of the electric field. To analyze the filtered signal, the measured signal was fitted to the estimated signal by means of kinetic modeling.

\section{Materials and Methods}

\subsection{Solar Cell Module Regeneration System}

To heat the solar cell module remotely, a system for the regeneration state application and real-time monitoring was developed, as shown in Figure 1. When the temperature of the solar cell module increases, the structure is likely to collapse because of a reduction in the strength of the ethylene-vinyl acetate (EVA) film. Thus, the front glass that bears the module load was placed at the bottom. Copper coils for applying the induction magnetic field were placed at the bottom of the solar cell module, and a half-bridge resonance circuit for applying alternating current to the coils was connected. A DC power supply for supplying current to the coils was connected to the resonance circuit, and the operation of the resonance circuit was controlled by a proportional-integral-differential (PID) controller. To measure the temperature of the solar cell, a thermocouple was attached to the surface of the Al electrode at the back of the solar cell.

The difference between the temperature emitted to the back sheet and the temperature of the solar cell was measured by assuming a general solar-cell module without a thermocouple. The operation of the resonance circuit was controlled through the feedback of the results of the infrared (IR) temperature sensor measured from the back of the back sheet. The operation of the resonance circuit was controlled by the feedback of the results of the infrared temperature sensor measured from the back of the back sheet. To examine the temperature distribution of the solar cell inside the module, image analysis was simultaneously conducted using a thermal imaging camera. After the target temperature was reached, 
a reverse-bias current was applied continuously to the solar cell by the source measure unit (SMU) through the ribbon connected at the front and rear electrodes of the solar cell.

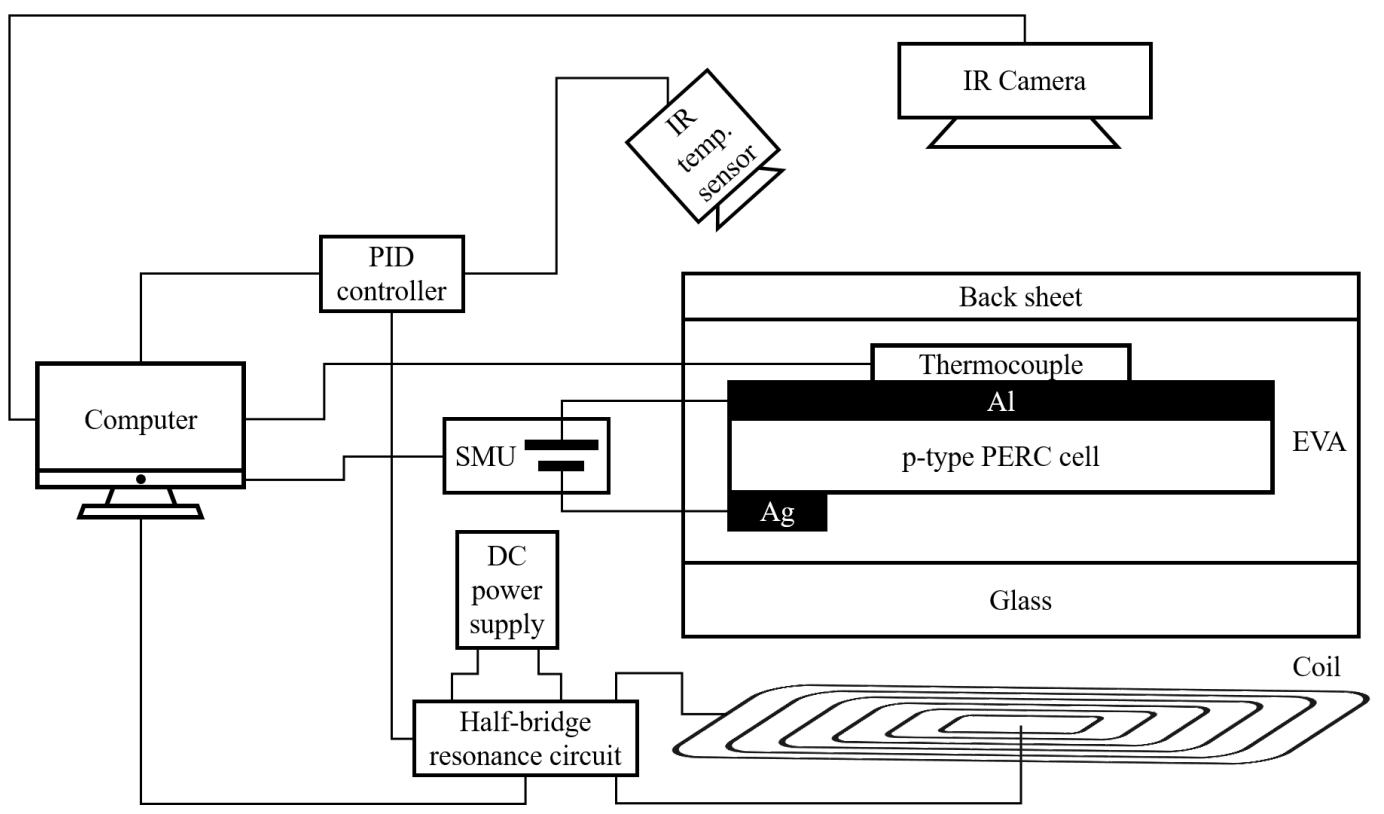

Figure 1. Passivated emmiter rear contact (PERC) solar cell module real-time regeneration state application and monitoring system.

\subsection{Solar Cell Module}

Figure 2 shows the solar cell module used in this study. The module was $200 \mathrm{~mm} \times 200 \mathrm{~mm}$ and included a five-busbar PERC solar cell. Ribbon strings were attached to the front and back of the PERC solar cell, and the strings were extended to the outside of the module for connection. To examine resonance heating by the induction magnetic field, a thin thermocouple was attached to the surface of the $\mathrm{Al}$ electrode at the back of the solar cell, and a lamination process was performed.

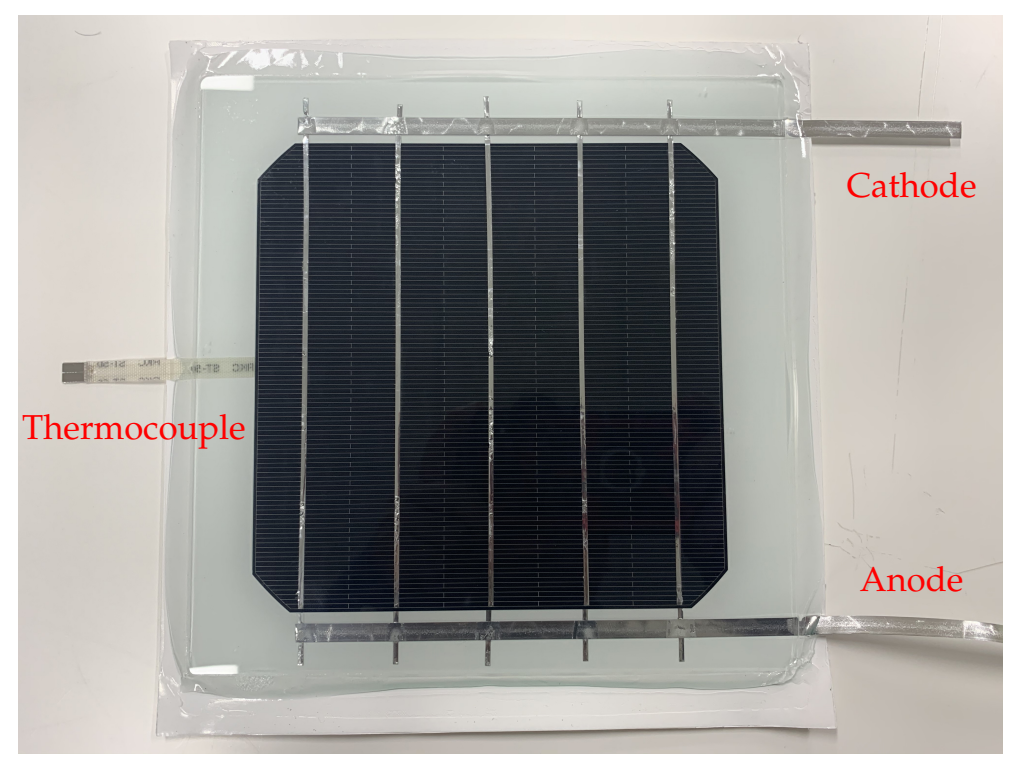

Figure 2. Small-area module specimen for experiment on applying regeneration state to PERC solar cell module.

The regeneration state was applied to the completed solar cell module by heating it to temperatures of 85,110 , and $120^{\circ} \mathrm{C}$ using the induction heater. The open-circuit voltage of the 
solar cell module was measured and recorded in $20 \mathrm{~ms}$ intervals to observe the real-time application state. The measurement error was less than $1 \mu \mathrm{V}$.

\subsection{Cyclic Reaction Model and Mathematical Process}

As for the LID and regeneration processes in the p-type PERC solar cell, the Herguth research group presented a three-state model based on the contents revealed so far, as shown in Figure 3. As can be seen from the figure, the three-state model defines the three states of initialization, degradation, and regeneration. In addition, the transition rates of each state are defined as $k_{1}, k_{2}, k_{3}, k_{i 1}, k_{i 2}$, and $k_{i 3}$. The process of changing from state A to state B represents the LID phenomenon that occurs when light is irradiated onto the solar cell. The rate of $k_{1}$ can be defined as the rate of LID occurrence. The rate of $k_{i 1}$ that occurs in the opposite direction can be defined as the recovery state in which the LID state returns to the initial state. The rate of $k_{2}$, a process where state $\mathrm{B}$ changes to state $\mathrm{C}$, can be defined as the regeneration state, and the rate of $k_{i 2}$ that occurs in the opposite direction can be defined as redegradation. $k_{3}$, a process where state $\mathrm{C}$ changes to state $\mathrm{A}$, can be defined as destabilization, while that in the opposite direction can be defined as stabilization. The Herguth research group could not observe the paths of $k_{3}$ and $k_{i 3}$, and thus, insisted on a consecutive reversible reaction model assuming they are nonexistent. In this study, all change paths were considered, and a numerical analysis model was created by applying a cyclic reaction model. The governing equations of the cyclic reaction model used in this study can be described as follows:

$$
\begin{aligned}
& \frac{\partial C_{a}}{\partial t}=k_{3} C_{c}-k_{i 3} C_{a}-k_{1} C_{a}+k_{i 1} C_{b} \\
& \frac{\partial C_{b}}{\partial t}=k_{1} C_{a}-k_{i 1} C_{b}-k_{2} C_{b}+k_{i 2} C_{c} \\
& \frac{\partial C_{c}}{\partial t}=k_{2} C_{b}-k_{i 2} C_{c}-k_{3} C_{c}+k_{i 3} C_{a}
\end{aligned}
$$

where $C_{i}(i=a, b, c)$ is the concentration of each state. The reaction rate constants can be expressed as $k_{i}(i=1,2,3)$, and the reverse reaction rate constants can be defined as $k_{i j}(j=1,2,3)$. As shown in Equation (1), cyclic reactions cannot be analyzed using general linear equations. In this study, Equation (1) was converted into the following matrix form by applying the eigenvalue method:

$$
\left(\begin{array}{ccc}
\lambda-k_{i 3}-k_{1} & k_{i 1} & k_{3} \\
k_{1} & \lambda-k_{i 1}-k_{2} & k_{i 2} \\
k_{i 3} & k_{2} & \lambda-k_{i 2}-k_{3}
\end{array}\right)\left(\begin{array}{c}
J_{a} \\
J_{b} \\
J_{c}
\end{array}\right)=0
$$

The three values of $\lambda_{i}$ can be defined by obtaining the determinant of the first matrix of Equation (2). If the general solution is applied, the change in concentration over time can be defined as follows:

$$
\begin{aligned}
& C_{a}=J_{a, 1} e^{-\lambda_{1} t}+J_{a, 2} e^{-\lambda_{2} t}+J_{a, 3} e^{-\lambda_{3} t} \\
& C_{b}=J_{b, 1} e^{-\lambda_{1} t}+J_{b, 2} e^{-\lambda_{2} t}+J_{b, 3} e^{-\lambda_{3} t} \\
& C_{c}=J_{c, 1} e^{-\lambda_{1} t}+J_{c, 2} e^{-\lambda_{2} t}+J_{c, 3} e^{-\lambda_{3} t}
\end{aligned}
$$

To solve Equation (3), an inverse Laplace transform was performed. Finally, the kinetic reaction model can be expressed as a function of the concentrations of states $\mathrm{A}, \mathrm{B}$, and $\mathrm{C}$; the reaction rate constants of $k_{1}, k_{2}, k_{3}, k_{i 1}, k_{i 2}$, and $k_{i 3}$; and time [12]. In this study, the regeneration process observed in real-time through the converted model was fitted using the cyclic reaction model. 


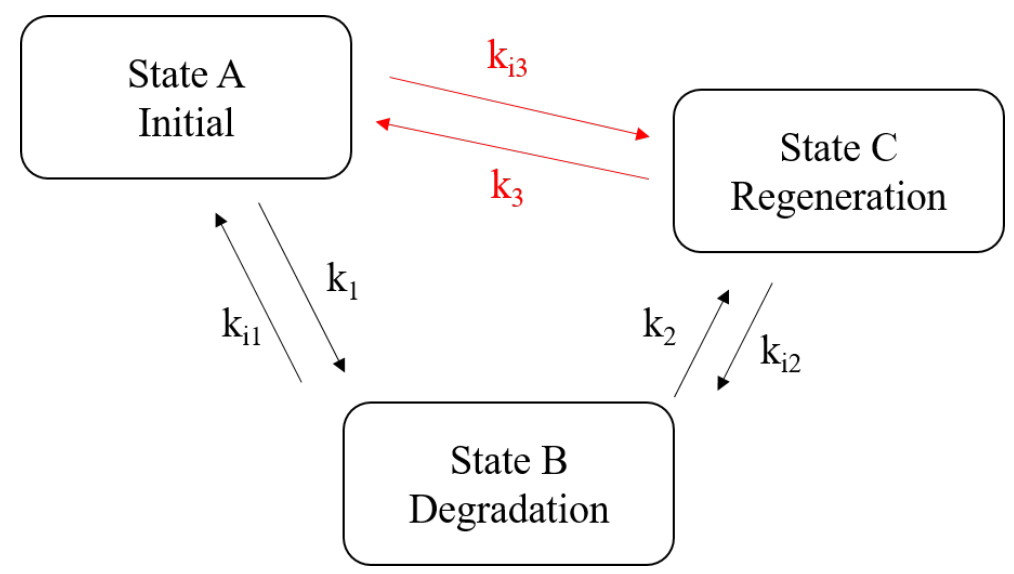

Figure 3. Three-state model structure related to light-induced degradation (LID) and regeneration of a solar cell.

\section{Results}

Prior to the regeneration process experiment, the temperature distribution at the back of the solar cell module was measured using a thermal imaging camera to examine whether only the solar cell inside the solar cell module was selectively heated. For the case where the temperature of the solar cell was set to $100{ }^{\circ} \mathrm{C}$, the temperature distribution at the back of the solar cell module was examined. Figure 4a shows the measurement results for the thermal imaging temperature. As can be seen from the figure, the distribution of the heat selectively applied to the solar cell inside the module was relatively uniform. Thus, an experiment on the application of the regeneration state was conducted.

As shown in Figure $4 \mathrm{~b}, \mathrm{c}$, the experiment was performed at 85,110 , and $120^{\circ} \mathrm{C}$, and the real-time monitoring results were examined using an induction heater to examine the regeneration state behavior with temperature. In the case of the real-time monitoring of the regeneration process of the solar cell module, signal processing was performed using high-pass and low-pass filters to remove the noise caused by the induction magnetic field, and it was possible to observe the changes in the open-circuit voltage in milliseconds through ultra-high-speed measurement at $20 \mathrm{~ms}$ intervals. For the fitting of the measured real-time analysis results with the cyclic reaction model, a nonlinear curve fitting method using the least-squares technique in MATLAB was applied.

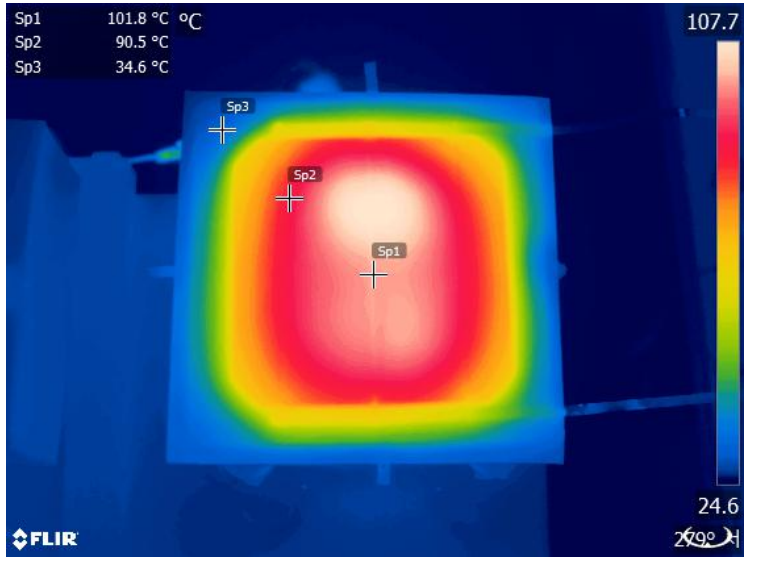

(a)

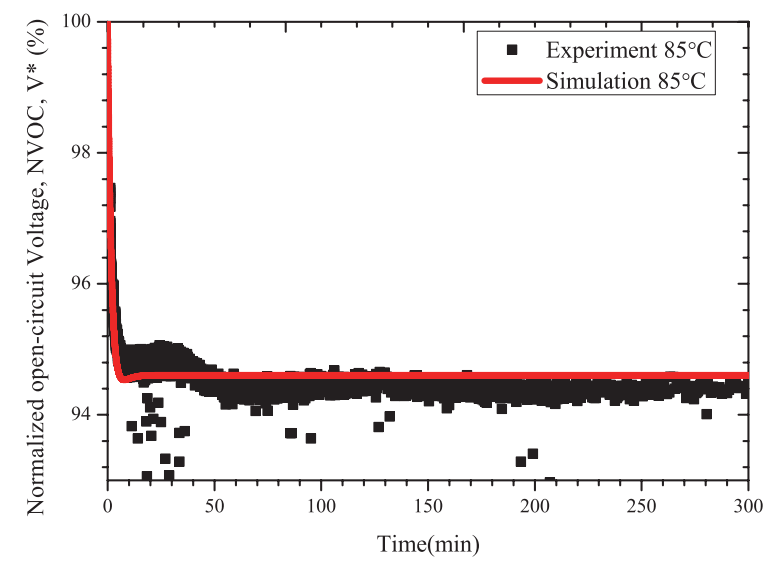

(b)

Figure 4. Cont. 


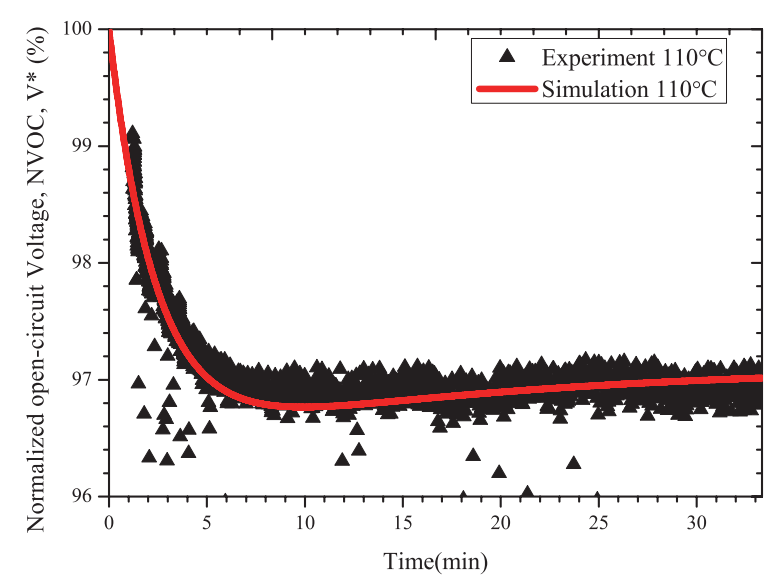

(c)

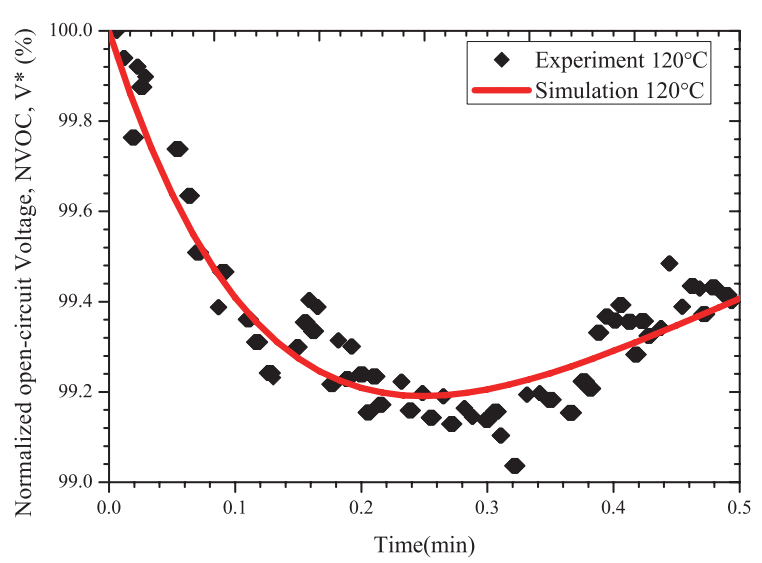

(d)

Figure 4. Real-time observation results of experiment on applying regeneration state to PERC solar cell module and cyclic reaction model simulation fitting. (a) Thermal image observation results of temperature distribution in one-cell PERC solar cell module subjected to remote heating using induction resonance circuit. Temperatures of $(\mathbf{b}) 85^{\circ} \mathrm{C}$, (c) $110{ }^{\circ} \mathrm{C}$, and (d) $120^{\circ} \mathrm{C}$.

\section{Discussion}

In this study, an experiment on applying the regeneration state to a solar cell module using remote heating was conducted, and kinetic modeling was performed using real-time analysis results. Figure 4a shows that the temperature variation of the solar cell was within $\pm 5{ }^{\circ} \mathrm{C}$ for the remote heating method using an induction magnetic field. This confirmed that the solar cell inside the module could be uniformly heated without using air heating. In addition, the amorphous polymer materials that were not targeted by resonance heating exhibited a temperature of $34.6^{\circ} \mathrm{C}$ under the condition that the temperature of the experimental space was maintained at $25^{\circ} \mathrm{C}$. This temperature increase did not appear to be caused by heating from the induction magnetic field, but caused by the conduction of the heat applied to the solar cell. A slight temperature increase appeared to be due to low heat transfer efficiency in the horizontal direction of the module surface, because the thermal conductivity of the encapsulant was extremely low.

This confirms that resonance heating has little impact on the damage to a solar cell module, and it appears that rapid cooling is also possible after the completion of the regeneration process because the average temperature of the encapsulant that surrounds the solar cell is low. While air heating consumes tens of hours and considerable energy until the solar cell is heated owing to the low thermal conductivity of the encapsulant, induction heating can selectively heat the target solar cell. Resonance heating can dramatically reduce the energy consumption because the heating duration is reduced to a few minutes and can minimize damage to the module owing to the short heat exposure time.

As shown in Figure $4 b, c$, the characteristics of the open-circuit voltage of the solar cell were normalized to analyze the process of applying the regeneration state to the solar cell module through the kinetic reaction model. The cyclic reaction model is a fully reversible state, in which the three states are fully circulated, and the sum of all the states is $100 \%$. To examine the simulation results of the inverse Laplace transform, the change in the normalized open-circuit voltage observed in real-time as a boundary condition, was defined as the sum of the change in the concentration of state $\mathrm{A}$ and that of state $\mathrm{C}$. Moreover, the concentration of state $\mathrm{B}$ was defined as the value obtained by subtracting the concentrations of states A and C from $100 \%$. Under the above boundary conditions, nonlinear curve fitting was performed using the least-squares method. The results were found to be almost consistent with the measured real-time open-circuit voltage data. The type of regeneration state varied depending on the temperature, as shown in Figure 4 b,c. The results were in good agreement with those of the cyclic reaction model as the magnitude of the temperature applied to the solar cell increased. 
To identify the results of the kinetic reaction model that agreed with the experiment results, cases that reached the steady state were compared, as shown in Figure 5a. As shown in the figure, the open-circuit voltage positions of the degradation point increased to $94.5 \%, 96.7 \%$, and $99.16 \%$ as the heat applied to the solar cell increased. This appeared to occur because the rates of recovery $\left(k_{i 1}\right)$ and regeneration $\left(k_{2}\right)$ followed the Arrhenius equation with increasing temperature compared to that of degradation $\left(k_{1}\right)$ in the three-state model. As the position of the degradation point increased, the time to reach the final regeneration stage decreased. It sharply decreased from $4554 \mathrm{~s}$ to $948 \mathrm{~s}$ and $101 \mathrm{~s}$ as the temperature increased. According to Equation (3), six reaction rate constants corresponding to transfer rates between each state were extracted by matching experimental data and calculated results with various temperatures. The activation energy of each reaction path was calculated from the reaction constants by using the Arrhenius equation:

$$
\log (k)=\log (A)-\frac{E_{a}}{2.30259 \times k_{b}} \times \frac{1}{T}
$$

Here, $k$ is the reaction rate constant, $A$ is a frequency factor that has the same units as the rate constant, $E_{a}$ is the activation energy, and $k_{b}$ is the Boltzmann constant. In Figure $5 \mathrm{~b}$, we calculated the activation energy of degradation (such as light-induced degradation) with temperature-dependent rate constants $k_{1}$. Plotting these reaction rates against the inverse temperature allows us to extract an activation energy of $0.414 \pm 0.07 \mathrm{eV}$, which agrees with results from other groups $(0.3-0.475 \mathrm{eV})[4,13-18]$.

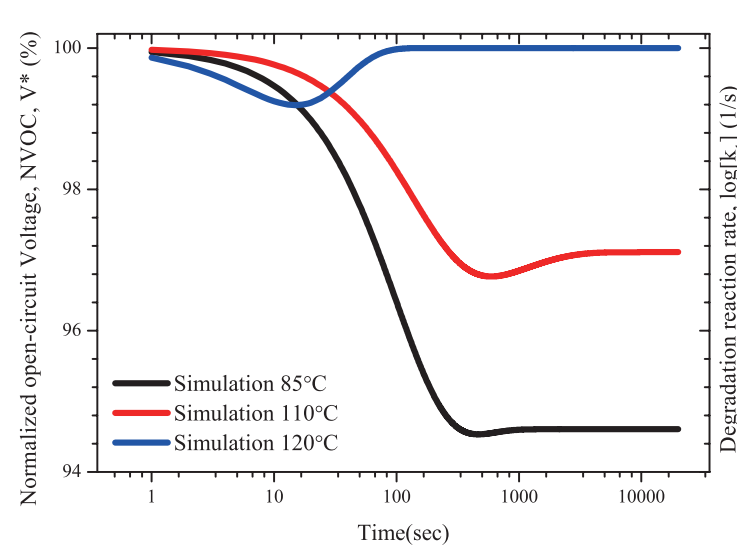

(a)

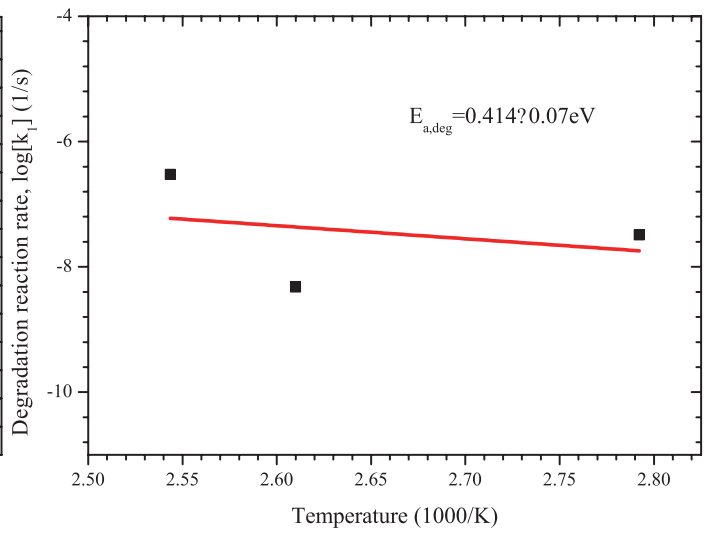

(b)

Figure 5. (a) Real-time regeneration application observation results and fitting dynamic simulation results of PERC solar cell module. (b) Rate constant distribution results by temperature for extracting LID activation energy generated during experiment on applying regeneration state to PERC solar cell module.

\section{Conclusions}

In this study, a regeneration process was applied to remove the light-induced degradation (LID) phenomenon generated in the p-type PERC solar cell module stage. Application of the regeneration process to the module stage has not previously been attempted because damage to the module encapsulant could not be avoided. In this study, air heating was not used, and remote resonance heating was applied using an induction magnetic field. Remote resonance heating can selectively heat the solar cell without heating the encapsulant through a reaction with the $\mathrm{Al}$ electrode at the back of the solar cell inside the module.

When the PERC solar cell module was fabricated in a small size and induction heating was applied, it was confirmed by thermal imaging camera analysis that only the solar cell was heated, and that other parts outside the solar cell were not heated because of the low thermal conductivity 
of the encapsulant. After a system was constructed to apply the regeneration state to the solar cell module, changes in the open-circuit voltage were measured and recorded in real-time. To analyze the measured real-time analysis data, a kinetic simulation analysis was conducted using the cyclic reaction model. A nonlinear curve fitting method that used the least-squares method was applied to fit the measurement and simulation results.

The results of applying 85,110 , and $120^{\circ} \mathrm{C}$ to the solar cell were in agreement with the simulation results. The activation energy of the degradation process was extracted using the rate constants obtained from the simulation results and the Arrhenius equation depending on the temperature, and the results were in agreement with those of previous studies. Based on the results of this study, a means of applying LID prevention after the solar-cell-module process was developed, and it was confirmed that the regeneration state can be applied through controlled temperature application conditions. The results of this study are expected to be utilized in various areas, such as applying the regeneration state to old solar cell modules and providing module distributors with LID prevention processing technology.

Author Contributions: S.M.K. conceived the main idea for remote direct heating method, performed the overall mathematical analysis, and wrote this paper; S.J. and J.K. contributed to manufacturing apparatus and analyzing the experimental results. Y.K. supported writing - review and editing. All authors have read and agreed to the published version of the manuscript.

Funding: This work was supported by the Korea Institute of Energy Technology Evaluation and Planning(KETEP) and the Ministry of Trade, Industry and Energy(MOTIE) of the Republic of Korea (No. 20183010014320), conducted under the framework of the Research and Development Program of the Korea Institute of Energy Research (B7-2426) and a grant(The core project-) from Gumi Core Components and Materials Technology Development Program of the Gumi Regional Government, 2019.

Acknowledgments: This work was supported by the Korea Institute of Energy Technology Evaluation and Planning(KETEP) and the Ministry of Trade, Industry and Energy(MOTIE) of the Republic of Korea (No. 20183010014320), conducted under the framework of the Research and Development Program of the Korea Institute of Energy Research (B7-2426) and a grant(The core project-564) from Gumi Core Components and Materials Technology Development Program of the Gumi Regional Government, 2019.

Conflicts of Interest: The authors declare no conflict of interest.

\section{Abbreviations}

The following abbreviations are used in this manuscript:

$\begin{array}{ll}\text { LCOE } & \text { Levelized Cost of Electricity } \\ \text { PERC } & \text { Passivated Emitter Rear Contact } \\ \text { LID } & \text { Light-Induced Degradation } \\ \mathrm{PID} & \text { Potential-Induced Degradation } \\ \mathrm{IR} & \text { Infra-Red } \\ \mathrm{Cz} & \text { Czochralski } \\ \mathrm{B}_{S} \mathrm{O}_{2 i} & \text { Boron Oxygen Dimer Complex } \\ \mathrm{B}_{s} & \text { Substitutional Boron } \\ \mathrm{O}_{2 i} & \text { Interstitial Oxygen Dimer } \\ \mathrm{AM} 1.5 \mathrm{G} & \text { Air Mass 1.5 Global tilt } \\ \mathrm{AC} & \text { Alternating Current } \\ \mathrm{DC} & \text { Direct Current } \\ \text { EVA } & \text { Ethylene Vinyl Acetate } \\ \mathrm{PID} & \text { Proportional-Integral-Differential } \\ \text { SMU } & \text { Source-Measure Unit }\end{array}$

\section{References}

1. International Technology Roadmap for Photovoltaic (ITRPV)—Results 2018 Including Maturity Report 2019; Technical Report; ITRPV-VDMA: Frankfurt, Germany, 2019. 
2. Weizer, V.; Brandhorst, H.; Broder, J.; Hart, R.; Lamneck, J. Photon-degradation effects in terrestrial silicon solar cells. J. Appl. Phys. 1979, 50, 4443-4449. [CrossRef]

3. Chen, X.; Yang, D.; Yu, X.; Zhu, X.; Chen, P. First-Principles Study of Interstitial Boron and Oxygen Dimer Complex in Silicon. Appl. Phys. Express 2013, 6, 041301. [CrossRef]

4. Du, M.H.; Branz, H.M.; Crandall, R.S.; Zhang, S. A New Mechanism for Non-Radiative Recombination at Light-Induced Boron-Oxygen Complexes in Silicon; National Renewable Energy Lab. (NREL): Golden, CO, USA, 2005.

5. Zhao, J.H.; Wang, A.H.; Green, M.A.; Ferrazza, F. 19.8\% efficient honeycomb textured multicrystalline and 24.4\% monocrystalline silicon solar cells. Appl. Phys. Lett. 1998, 73, 1991-1993. [CrossRef]

6. Knobloch, J.; Glunz, S.; Henninger, V.; Warta, W.; Wettling, W.; Schomann, F.; Schmidt, W.; Endros, A.; Münzer, K. 21\% efficient solar cells processed from Czochralski grown silicon. In Proceedings of the 13th European Photovoltaic Solar Energy Conference, Nice, France, 23-27 October 1995; pp. 9-12.

7. Sterk, S.; Münzer, K.; Glunz, S. Investigation of the degradation of crystalline silicon solar cells. In Proceedings of the 14th European Photovoltaic Solar Energy Conference, Barcelona, Spain, 30 June-4 July 1997; Volume 85.

8. Fischer, H.; Pschunder, W. Investigation of photon and thermal induced changes in silicon solar cells. In Proceedings of the 10th IEEE Photovoltaic Specialist Conference (PVSC), New York, NY, USA, 13-15 November 1973.

9. Herguth, A.; Schubert, G.; Kaes, M.; Hahn, G. A new approach to prevent the negative impact of the metastable defect in boron doped Cz silicon solar cells. In Proceedings of the 2006 IEEE 4th World Conference on Photovoltaic Energy Conference, Waikoloa, HI, USA, 7-12 May, 2006; Volume 1, pp. 940-943.

10. Herguth, A.; Schubert, G.; Kaes, M.; Hahn, G. Avoiding boron-oxygen related degradation in highly boron doped Cz silicon. In Proceedings of the 21st European Photovoltaic Solar Energy Conference: 21th EC PVSEC, Dresden, Germany, 4-8 September 2006; pp. 530-537.

11. Fertig, F.; Greulich, J.; Broisch, J.; Biro, D.; Rein, S. Stability of the regeneration of the boron-oxygen complex in silicon solar cells during module integration. Sol. Energy Mater. Sol. Cells 2013, 115, 189-198. [CrossRef]

12. Kim, S.M.; Chun, S.; Bae, S.; Park, S.; Kang, M.G.; Song, H.E.; Kang, Y.; Lee, H.S.; Kim, D. Light-induced degradation and metastable-state recovery with reaction kinetics modeling in boron-doped Czochralski silicon solar cells. Appl. Phys. Lett. 2014, 105, 083509. [CrossRef]

13. Bothe, K.; Hezel, R.; Schmidt, J. Understanding and reducing the boron-oxygen-related performance degradation in Czochralski silicon solar cells. In Solid State Phenomena; Trans Tech Publications: Stafa-Zurich, Switzerland, 2004; Volume 95, pp. 223-228.

14. Dubois, S.; Enjalbert, N.; Garandet, J. Slow down of the light-induced-degradation in compensated solar-grade multicrystalline silicon. Appl. Phys. Lett. 2008, 93, 103510. [CrossRef]

15. Schmidt, J.; Bothe, K.; Hezel, R. Formation and annihilation of the metastable defect in boron-doped Czochralski silicon. In Proceedings of the Conference Record of the Twenty-Ninth IEEE Photovoltaic Specialists Conference, New Orleans, LA, USA, 19-24 May 2002; pp. 178-181.

16. Glunz, S.; Schaffer, E.; Rein, S.; Bothe, K.; Schmidt, J. Analysis of the defect activation in Cz-silicon by temperature-dependent bias-induced degradation of solar cells. In Proceedings of the IEEE 3rd World Conference onPhotovoltaic Energy Conversion, Osaka, Japan, 11-18 May 2003; Volume 1, pp. 919-922.

17. Palmer, D.W.; Bothe, K.; Schmidt, J. Kinetics of the electronically stimulated formation of a boron-oxygen complex in crystalline silicon. Phys. Rev. B 2007, 76, 035210. [CrossRef]

18. Bothe, K.; Schmidt, J. Electronically activated boron-oxygen-related recombination centers in crystalline silicon. J. Appl. Phys. 2006, 99, 013701. [CrossRef]

(c) 2019 by the authors. Licensee MDPI, Basel, Switzerland. This article is an open access article distributed under the terms and conditions of the Creative Commons Attribution (CC BY) license (http:/ / creativecommons.org/licenses/by/4.0/). 